\title{
Pathological Validity of Using Near-infrared Fluorescence Imaging for Securing Surgical Margins During Liver Resection
}

\author{
YOSHIHIKO TASHIRO ${ }^{1}$, TAKESHI AOKI ${ }^{1}$, TAKAHITO HIRAI ${ }^{1}$, TOMOTAKE KOIZUMI ${ }^{1}$, DOAA A. MANSOU ${ }^{1,2}$, \\ TOMOKAZU KUSANO ${ }^{1}$, KAZUHIRO MATSUDA ${ }^{1}$, KOSUKE YAMADA ${ }^{1}$, KOJI NOGAKI ${ }^{1}$, TOMOKI HAKOZAKI ${ }^{1}$, \\ YUSUKE WADA ${ }^{1}$, HIDEKI SHIBATA ${ }^{1}$, KODAI TOMIOKA ${ }^{1}$, TATSUYA YAMAZAKI $^{1}$, KAZUHIKO SAITO $^{1}$, \\ AKIRA FUJIMORI $^{1}$, YUTA ENAMI $^{1}$, ROBERT M. HOFFMAN ${ }^{3,4}$ and MASAHIKO MURAKAMI ${ }^{1}$ \\ ${ }^{1}$ Department of General and Gastroenterological Surgery, Showa University School of Medicine, Tokyo, Japan; \\ ${ }^{2}$ General Surgery Department, Cairo University Hospitals, Kasr Alainy, Al-Saray street, El-Manial, Cairo, Egypt; \\ ${ }^{3}$ Department of Surgery, University of California, San Diego, CA, U.S.A.; \\ ${ }^{4}$ AntiCancer Inc., San Diego, CA, U.S.A.
}

\begin{abstract}
Background/Aim: This study investigated the use of near-infrared fluorescent imaging for securing safe margins during liver resection. Patients and Methods: This study included 125 patients who underwent liver tumor resection in 2014-2018. Indocyanine green testing was performed 2-14 days before surgery. Histopathological specimens of hepatocellular carcinoma (HCC) and colorectal liver metastasis (CRLM) were evaluated using fluorescent microscopy. Results: Fluorescence microscopy identified signals in 26/53 (49.0\%) and 36/72 (50\%) cases of HCC and CRLM, respectively. HCC demonstrated total, partial, rim, and combined fluorescence patterns; CRLM uniformly demonstrated rim fluorescence. Although rim fluorescence was seen in both HCC and CRLM, no malignancy was confirmed pathologically in the peritumoral area demonstrating fluorescence. The median widths of fluorescence from the tumor edge in HCC and CRLM were $1227.5 \mu \mathrm{m}$ and $1608 \mu \mathrm{m}$, respectively, with no significant difference. Conclusion: Near-infrared fluorescent imaging can reliably detect safe surgical margins intraoperatively during liver resection.
\end{abstract}

Indocyanine green (ICG) binds to proteins in the blood and emits fluorescent signals at near-infrared (NIR) wavelength (1). ICG fluorescence imaging is widely applied in various surgical fields. In liver surgery, ICG fluorescent imaging is

This article is freely accessible online.

Correspondence to: Takeshi Aoki, Department of General and Gastroenterological Surgery, Showa University School of Medicine, 1-5-8 Hatanodai, Shinagawa-Ku, Tokyo 142-8666, Japan. Tel: +81 337848000, Fax: +81 489653019, e-mail: takejp@med.showa-u.ac.jp

Key Words: Surgical margin, ICG fluorescence-guided surgery, fluorescence width, fluorescence pattern, laparoscopic liver resection. used in tumor detection, tattooing, biliary tract contrast, and liver segmentation (2-4).

ICG is taken up by hepatocytes and is excreted in the bile; however, the ICG excretion process inside and around the tumor is abnormal, and is characterized by stagnation due to disordered excretion (5). On irradiating the ICG stagnated inside and around the tumor with NIR light, it emits a fluorescent signal. This is useful for identifying tumors intraoperatively $(6,7)$.

Intraoperative ultrasonography (IOUS) and palpation are usually performed for the identification of liver tumors during the procedure. Laparoscopic liver resection has become popular in recent years; however, palpation and visualization of liver tumors with IOUS is difficult in laparoscopic surgery, owing to the operational difficulties of laparoscopic ultrasonography. Therefore, the identification of liver tumors using ICG fluorescence signals is an extremely useful tool in laparoscopic liver surgery.

Aoki et al. reported that ICG fluorescent imaging may be used as navigation technology for determining the surgical margins of tumors (8). Previous reports have focused on the macro- and microscopic features of liver cancer resected under fluorescence guidance and there is a general agreement that the surgical margin may be jeopardized if fluorescence signals are exposed on the transection plane. Liver parenchymal transections are therefore carefully performed to prevent exposure of fluorescence $(5,9-12)$. However, the pathological validity of using NIR fluorescence to secure the surgical margin has not been confirmed by examining the fluorescence range under fluorescence microscopy before.

In this study, we evaluated the relationship between NIR fluorescence imaging and surgical margin pathology by investigating the fluorescence range and pattern, and microscopically validating the surgical margin with fluorescence microscopy. 


\section{Patients and Methods}

This study was approved by the Ethics Committee of Showa University (approval number: 3008) and was performed according to the guidelines of the Declaration of Helsinki.

Patients. In this retrospective study, we included 125 patients who underwent liver resection for hepatocellular carcinoma (HCC, $n=53$ ) or colorectal liver metastasis (CRLM, $\mathrm{n}=72$ ) at the Department of General and Gastroenterological Surgery of Showa University, between January 2014 and December 2018. The patient characteristics are shown in Table I.

Fluorescence microscopy. The pathology specimens were obtained at Showa University, and were fixed with formalin, sectioned at a thickness of $7 \mu \mathrm{m}$, and stained with hematoxylin and eosin. Tissue sections were selected in which the tumor was surrounded by normal liver tissue.

Pathology images were visualized under a fluorescence microscope (BZ-X800; Keyence, Osaka, Japan) using the navigation function, with a replaced objective lens $(x 1)$. The exposure time was $2 \mathrm{~s}$. Each image was prepared by tiling observed images using the joint imaging system of the built-in fluorescence microscope. An ICG filter (OP-87767; Keyence) was used as an NIR light source to observe the ICG fluorescence signal directly in the pathology specimen, without using fluorescence antibodies. The width of fluorescence area around tumor was measured using the analysis application (Keyence, Osaka, Japan).

Classification of fluorescence patterns of liver cancer by fluorescence microscopy. The fluorescence pattern in each case was classified as either total fluorescence i.e. all the cancer tissue showed uniform fluorescence, partial fluorescence i.e. part of the cancer tissue showed fluorescence, rim fluorescence i.e. only the surrounding liver parenchyma showed fluorescence, or combined fluorescence i.e. both the cancer tissue and surrounding liver parenchyma showed fluorescence (Figure 1). The rim-negative group included total and partial fluorescence types, while the rim-positive group included rim fluorescence with total, or partial fluorescence types.

Procedure. The preoperative ICG test for liver function $(0.5 \mathrm{mg} / \mathrm{kg}$ i.v., Diagnogreen; Daiichi Sankyo, Tokyo, Japan) was usually administered 2-14 days before the surgery. ICG was only administered at that time, and not intraoperatively.

Preoperative image simulation was performed using the volume analyzer Synapse Vincent (Fujifilm Medical, Tokyo, Japan), which is a three-dimensional analysis system for optimal planning of port placement and enhanced visualization of vessels, bile ducts, and tumors. IOUS was performed before and during liver resection for the detection of tumors.

The PINPOINT Endoscopic Fluorescence Imaging System (Stryker, Kalamazoo, MI, USA) was used to detect the tumors and evaluate the surgical margins, and the liver parenchyma was carefully transected to prevent exposure of the fluorescent signal from the tumors. After liver resection, the absence of ICG fluorescence in the transected plane of the residual liver was confirmed. Surgical specimens were cut to include the maximum diameter of each tumor based on immediate gross inspection using the fluorescent imaging system in the operating room (SPY Portable Handheld Imaging System; Stryker).
Table I. Patient characteristics.

\begin{tabular}{|c|c|c|c|}
\hline & $\begin{array}{l}\mathrm{HCC} \\
\mathrm{n}=26\end{array}$ & $\begin{array}{c}\text { CRLM } \\
\mathrm{n}=36\end{array}$ & $p$-Value \\
\hline \multicolumn{4}{|l|}{ Age, years } \\
\hline Median (range) & $72(59-85)$ & $67.5(34-85)$ & 0.04 \\
\hline \multicolumn{4}{|l|}{ Gender, n } \\
\hline Male & 18 & 23 & 0.78 \\
\hline Female & 8 & 13 & \\
\hline \multicolumn{4}{|c|}{ Background liver status, $n$} \\
\hline Normal & 10 & 35 & $<0.001$ \\
\hline Chronic hepatitis & 14 & 1 & \\
\hline Cirrhosis & 2 & 0 & \\
\hline \multicolumn{4}{|l|}{ Child-Pugh score, $\mathrm{n}$} \\
\hline $\mathrm{A}$ & 23 & 36 & 0.07 \\
\hline B & 3 & 0 & \\
\hline \multicolumn{4}{|l|}{ ICG R15 } \\
\hline Median (range) & $13(4-38)$ & $9(2-34)$ & 0.03 \\
\hline \multicolumn{4}{|c|}{$\begin{array}{l}\text { Days between ICG } \\
\text { injection and surgery }\end{array}$} \\
\hline Median (range) & $5(2-40)$ & $5(2-34)$ & 0.81 \\
\hline \multicolumn{4}{|l|}{ Procedure } \\
\hline LLR & 11 & 19 & 0.8 \\
\hline VATS-H & 3 & 2 & \\
\hline Laparotomy & 12 & 15 & \\
\hline $\mathrm{Hr} 0$ & 16 & 27 & 0.27 \\
\hline Hrs & 5 & 3 & \\
\hline Hr-LLS & 1 & 3 & \\
\hline $\mathrm{Hr} 1$ & 1 & 1 & \\
\hline $\mathrm{Hr} 2,3$ & 3 & 2 & \\
\hline \multicolumn{4}{|l|}{ Size of tumor, mm } \\
\hline Median (range & $25(5-130)$ & $30(10-75)$ & 0.24 \\
\hline
\end{tabular}

ICG R15: Indocyanine green retention rate at 15 minutes; LLR: laparoscopic liver resection; VATS-H: video-assisted thoracoscopic surgery hepatectomy; Hr0: partial resection; Hrs: subsegmentectomy; Hr-LLS: left lateral segmentectomy; $\mathrm{Hr} 1$ : segmentectomy; $\mathrm{Hr} 2$. bisegmentectomy; $\mathrm{Hr} 3$ : trisegmentectomy. Bold values indicate statistical significance.

Statistical analysis. Continuous data were expressed as median (range) values. Categorical exact data and continuous data were compared using the Fisher exact and Wilcoxon rank-sum tests, respectively. A pvalue $<0.05$ was considered statistically significant.

\section{Results}

Patients characteristics. We evaluated the pathology of 26 and 36 surgical specimens of HCC and CRLM, respectively, under fluorescence microscopy. Table I summarizes the characteristics of the patients with HCC and CRLMs. Patients with HCC had a significantly higher prevalence of chronic hepatitis and cirrhosis and higher ICGR15 than those with CRLM (Table I).

Classification fluorescence patterns of liver cancer by fluorescence microscopy and its characteristics. The fluorescence patterns observed in HCC cases were as 

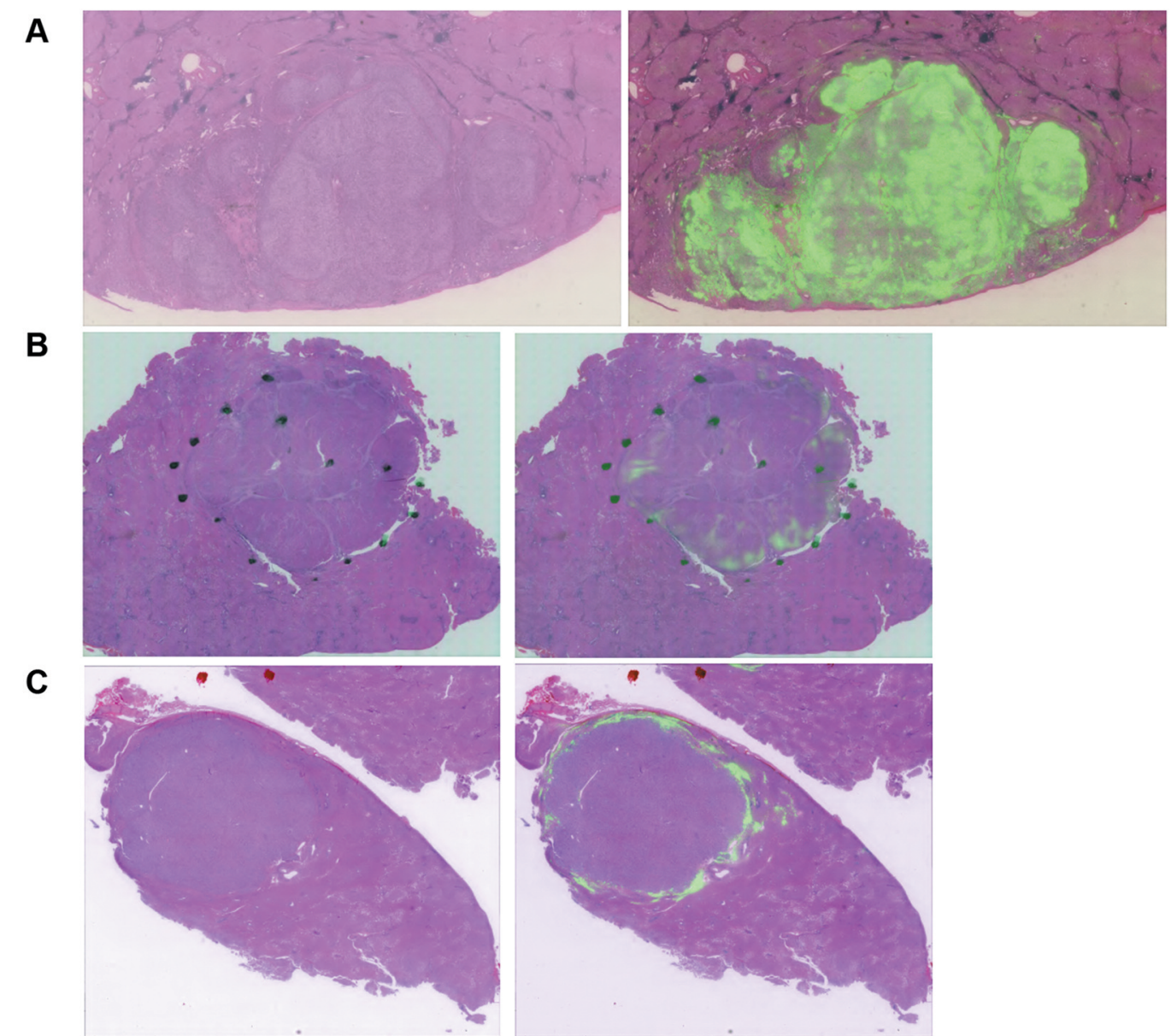

D
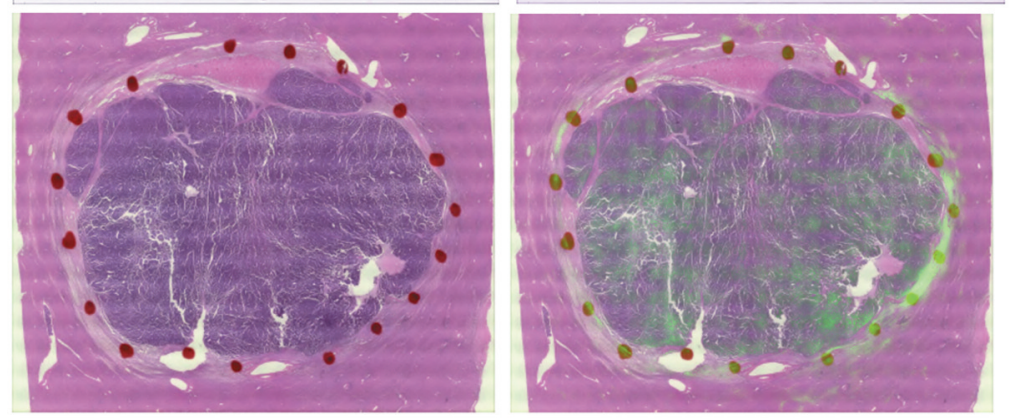

E
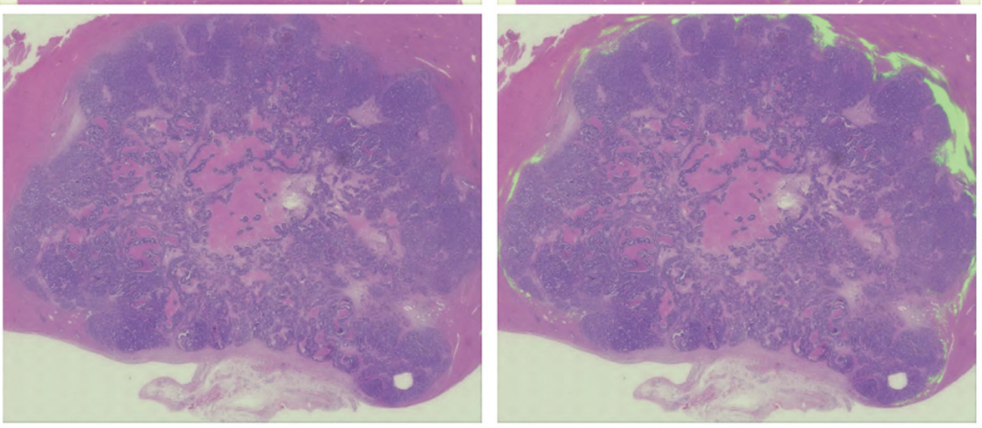

Figure 1. Pathological indocyanine green (ICG) fluorescence patterns in hepatocellular carcinoma (HCC) and colorectal liver metastasis (CRLM). Left panel: Cancer tissues stained with hematoxylin and eosin. Right panel: Images merged with the ICG fluorescence in the cancer tissues. All specimens were directly observed using $a \times 1$ objective lens under the ICG filter. A: Total fluorescent type; moderately differentiated HCC. B: Partial type; well-differentiated HCC.C: Rim type; moderately differentiated HCC. D: Combined type; moderately differentiated HCC. E: Rim type; metastasis of colon carcinoma. 
Table II. Microscopic fluorescence pattern of hepatocellular carcinomas.

\begin{tabular}{|c|c|c|c|c|c|}
\hline & & \multicolumn{4}{|c|}{ Fluorescent type } \\
\hline & & Total $(n=8)$ & Partial $(n=3)$ & $\operatorname{Rim}(n=10)$ & Combined $(n=5)$ \\
\hline ICG R15 & Median (range) & $11.5(4-21)$ & $13(9-18)$ & $18.5(5-38)$ & $11(5-19)$ \\
\hline \multirow{2}{*}{ Child-Pugh score, $\mathrm{n}$} & A & 7 & 3 & 9 & 4 \\
\hline & B & 1 & 0 & 1 & 1 \\
\hline Days between ICG injection and surgery & Median (range) & $4(2-20)$ & $21.5(3-40)$ & $4(2-20)$ & $6(4-12)$ \\
\hline \multirow[t]{2}{*}{ Cancer cell differentiation } & Well & 4 & 0 & 1 & 2 \\
\hline & Moderate or poor & 4 & 3 & 9 & 3 \\
\hline \multirow[t]{3}{*}{ Background liver status } & Normal & 2 & 2 & 5 & 1 \\
\hline & Chronic hepatitis & 6 & 1 & 4 & 3 \\
\hline & Cirrhosis & 0 & 0 & 1 & 1 \\
\hline \multirow[t]{5}{*}{ Fibrosis stage } & F0 & 1 & 0 & 1 & 2 \\
\hline & $\mathrm{F} 1$ & 0 & 0 & 5 & 1 \\
\hline & $\mathrm{F} 2$ & 0 & 1 & 0 & 0 \\
\hline & F3 & 3 & 1 & 2 & 1 \\
\hline & $\mathrm{F} 4$ & 2 & 1 & 2 & 1 \\
\hline Size of tumor, mm & Median (range) & $25(13-80)$ & $37(17-120)$ & $19(5-47)$ & $45(18-130)$ \\
\hline
\end{tabular}

ICG R15: Indocyanine green retention rate at $15 \mathrm{~min}$.

follows: Total in eight cases, partial in three, rim in 10, and combined type in five (total plus rim in two; partial plus rim in three) (Table II). Only the rim fluorescence type was observed in all CRLM cases.

Well-differentiated carcinomas were more common in HCCs with a total fluorescent type than in HCCs with other fluorescent types $(p<0.001$; Table III).

Patients with HCC were classified into two groups, those with rim-positive fluorescence and those with rim-negative fluorescence. The rim-negative group included total and partial fluorescent types, while the rim-positive group included rim fluorescence with total, or partial fluorescence types. The stage and grade of fibrosis were significantly higher in the rim-positive than in the rim-negative group $(p=0.033$; Table IV).

Width of fluorescence surrounding tumors. In CRLM cases, the width of the fluorescence from tumors was $\geq 1 \mathrm{~mm}$ from the tumor edge in $28(77.8 \%)$ cases and $<1 \mathrm{~mm}$ in eight (22.2\%) cases (Table V). All cases of CRLM exhibited the rim fluorescence pattern, and the median width of fluorescence from the tumor edge was $1608 \mu \mathrm{m}$ (range $=304$ $7467 \mu \mathrm{m})$ (Table VI).

In HCC, 11 cases $(42.3 \%)$ had a rim-negative fluorescence pattern, i.e. the width of fluorescence surrounding the tumor was 0 . In HCC cases with rim-positive fluorescence patterns (15 cases), the fluorescence width was $\geq 1 \mathrm{~mm}$ from the tumor edge in $11(42.3 \%)$ cases and $<1 \mathrm{~mm}$ in four (15.4\%) cases. Patients with HCC, including those with a rim-negative fluorescence pattern, had a significantly higher prevalence of fluorescence width $<1 \mathrm{~mm}$ than those with CRLM. In HCC, the median width of fluorescence from the edge of the tumor was $1,227.5 \mu \mathrm{m}$ (range $=0-110,100 \mu \mathrm{m}$ ). However, there was no significant difference in the width of fluorescence between HCC and CRLM (Table VI). The were no malignant findings histopathologically in the area with fluorescent signals surrounding the tumor in either HCC nor CRLM cases (Figures 2 and 3). Fluorescence microscopy did not identify fluorescent signals in 27 out of $53(51.0 \%)$ cases of HCC and 36 out of 72 (50\%) cases of CRLM. Detection by fluorescence microscopy was not affected by liver function (Tables VII and VIII).

\section{Discussion}

The goal of surgical resection in cancer is to obtain an R0 status, which is characterized by negative surgical margins. $\mathrm{R} 1$ resection is characterized by positive tumor margins and should therefore be avoided.

Since the first report on laparoscopic wedge resection of the liver in 1991 (13), this procedure has become widely popular. Some reports suggest that for HCC and CRLM, laparoscopic liver resection is comparable to open hepatectomy in terms of long-term outcomes, and offers beneficial short-term outcomes (14-16). Palpation and IOUS are the primary methods for detecting tumors, confirming tumor locations, and securing the surgical margins. However, laparoscopic ultrasonography is difficult to perform, and information obtained by palpation using laparoscopic forceps during liver resection is extremely limited; this may increase the risk of positive surgical margins.

Currently, ICG fluorescence imaging is widely used in fluorescence-guided surgery for breast (17), gastric (18), and 
Tashiro et al: Fluorescence Microscopy of Liver Tumors

Table III. Characteristics of total fluorescent type (total type, total+rim type) versus the other patterns (partial type, partial+rim type, rim type) in hepatocellular carcinomas.

\begin{tabular}{|c|c|c|c|c|}
\hline & & Total fluorescent type $(\mathrm{n}=11)$ & Other type $(n=15)$ & $p$-Value \\
\hline ICG R15 & Median (range) & $11(4-21)$ & $15.5(5-38)$ & 0.2 \\
\hline \multirow[t]{2}{*}{ Child-Pugh score, $\mathrm{n}$} & A & 10 & 13 & $>0.99$ \\
\hline & $\mathrm{B}$ & 1 & 2 & \\
\hline Days between ICG injection and surgery & Median (range) & $5(2-20)$ & $4.5(2-40)$ & 0.8 \\
\hline \multirow[t]{2}{*}{ Cancer cell differentiation, $\mathrm{n}$} & well & 5 & 0 & 0.007 \\
\hline & Moderate or poor & 6 & 15 & \\
\hline \multirow[t]{3}{*}{ Background liver status } & Normal & 3 & 7 & 0.44 \\
\hline & Chronic hepatitis & 8 & 6 & \\
\hline & Cirrhosis & 0 & 2 & \\
\hline \multirow[t]{5}{*}{ Fibrosis stage } & Fo & 3 & 1 & 0.67 \\
\hline & $\mathrm{F} 1$ & 0 & 6 & \\
\hline & $\mathrm{F} 2$ & 0 & 1 & \\
\hline & F3 & 4 & 3 & \\
\hline & F4 & 2 & 4 & \\
\hline Size of tumor, mm & Median (range) & $25(13-130)$ & $20(5-120)$ & 0.61 \\
\hline
\end{tabular}

ICG R15: indocyanine green retention rate at 15 minutes. Bold value indicates statistical significance.

Table IV. Characteristics of rim-negative (total or partial type) and rim-positive (rim type, total or parial+rim type) patterns in hepatocellular carcinomas.

\begin{tabular}{|c|c|c|c|c|}
\hline & & Rim-negative type $(\mathrm{n}=11)$ & Rim-positive type $(\mathrm{n}=15)$ & $p$-Value \\
\hline ICG R15 & Median (range) & $12(4-21)$ & $14(5-38)$ & 0.36 \\
\hline \multirow[t]{2}{*}{ Child-Pugh score, n } & A & 10 & 13 & $>0.99$ \\
\hline & $\mathrm{B}$ & 1 & 2 & \\
\hline Days between ICG injection and surgery & Median (range) & $4(2-40)$ & $5(2-20)$ & 0.82 \\
\hline \multirow[t]{2}{*}{ Cancer cell differentiation } & Well & 4 & 3 & 0.4 \\
\hline & Moderate or poor & 7 & 12 & \\
\hline \multirow[t]{3}{*}{ Background liver status } & Normal & 4 & 6 & $>0.99$ \\
\hline & Chronic hepatitis & 7 & 7 & \\
\hline & Cirrhosis & 0 & 2 & \\
\hline \multirow[t]{5}{*}{ Fibrosis stage } & F0 & 1 & 3 & 0.033 \\
\hline & $\mathrm{F} 1$ & 0 & 6 & \\
\hline & $\mathrm{F} 2$ & 1 & 0 & \\
\hline & F3 & 4 & 3 & \\
\hline & $\mathrm{F} 4$ & 3 & 3 & \\
\hline Size of tumor (mm) (range) & Median (range) & $25(13-80)$ & $20(5-130)$ & 0.63 \\
\hline
\end{tabular}

ICG R15: Indocyanine green retention rate at $15 \mathrm{~min}$.

esophageal (19) cancers, and for vascular surgery (20). It is also used in the pancreatic-biliary liver surgical field for the detection of liver tumors (6), pancreatic cancer (10), tattooing for liver segmentation (2), biliary tract surgery (4), and bile leakage (21).

In ICG fluorescence-guided liver resection, the absence of fluorescent signals on the resected surface indicates a secure surgical margin (8). In this study, the surgical margin was secured in all cases where ICG fluorescence was performed. This confirmed the utility of the ICG fluorescence method in securing the surgical margin. To the best of our knowledge, this is the first study to investigate the pathological validity of using the ICG fluorescence signal as an indicator of the surgical margin during liver resection.

The ICG fluorescence signal patterns differ according to carcinoma type. Certain institutes recently reported macroscopic fluorescence patterns and features in HCC that were genetically evaluated $(6,9-11,21)$. Ishizawa et al. reported that well- or moderately differentiated HCC mostly displayed uniform or partial-type fluorescence, while poorly differentiated HCC mostly displayed rim-type fluorescence, as the degree of $\mathrm{Na}(+)$ taurocholate co-transporting polypeptide (NTCP) and 
Table V. Characteristics of colorectal liver metastasis by width of fluorescence.

\begin{tabular}{llccc}
\hline Characteristic & & $<1 \mathrm{~mm}(\mathrm{n}=8)$ & $\geq 1 \mathrm{~mm}(\mathrm{n}=28)$ & $p$-Value \\
\hline ICG R15 & Median (range) & $10.5(6-34)$ & $8(2-20)$ & $\mathbf{0 . 0 4}$ \\
Days between ICG injection and surgery & Median (range) & $6.5(3-25)$ & $5(2-29)$ & 0.47 \\
LHL15 of 99mTc-GSA liver scintigraphy & Median (range) & $0.889(0.781-0.925)$ & $0.887(0.845-0.947)$ & \\
Tumor marker & & & $11.2(1.9-930.8)$ & 0.64 \\
CEA, ng/ml & Median (range) & $14(2.7-127.8)$ & $16.2(2-57,057.8)$ & 0.54 \\
CA19-9, U/ml & Median (range) & $6.7(2-1,804)$ & $28(10-55)$ & 0.6 \\
Size of tumor, mm & Median (range) & $35(10-60)$ & \\
\hline
\end{tabular}

ICG R15: Indocyanine green retention rate at 15 minutes; CEA: carcinoembryonic antigen; CA19-9: carbohydrate antigen 19-9; LHL15: uptake ratio of the liver to the liver plus heart at $15 \mathrm{~min}$; ${ }^{99 \mathrm{~m} T c-G S A}$ : technetium-99m-diethylenetriaminepentaacetic acid-galactosyl human serum albumin. Bold value indicates statistical significance.

Table VI. Fluorescence width around tumors of hepatocellular carcinoma (HCC) and colorectal liver metastasis (CRLM).

\begin{tabular}{|c|c|c|c|}
\hline Fluorescence width & $\mathrm{HCC}(\mathrm{n}=26)$ & CRLM $(n=36)$ & $p$-Value \\
\hline$<1 \mathrm{~mm}$ & 4 & 8 & \\
\hline$\geq 1 \mathrm{~mm}$ & 11 & 28 & \\
\hline $0 \mathrm{~mm}$ & 11 & 0 & 0.007 \\
\hline Median from the edge of rim pattern tumors (range), $\mu \mathrm{m}$ & $2159(378-110,100)$ & $1,608(304-7,467)$ & 0.75 \\
\hline Median fluorescence width from edge of whole tumors (range), $\mu \mathrm{m}$ & $1227.5(0-110,100)$ & $1,608(304-7,467)$ & 0.11 \\
\hline
\end{tabular}

Bold value indicates statistical significance.

Table VII. Exhibition of fluorescence signal in hepatocellular carcinoma and colorectal liver metastasis as detected by fluorescence microscopy after i.v. administration of $0.5 \mathrm{mg} / \mathrm{kg}$ indocyanine green.

\begin{tabular}{lcccccc}
\hline & Detection $(\mathrm{n}=26)$ & Non-detection $(\mathrm{n}=27)$ & $p$-Value & Detection $(\mathrm{n}=36)$ & Non-detection $(\mathrm{n}=36)$ & $p$-Value \\
\hline ICG R15 & & & & & \\
$\quad$ Median (range) & $13(4-38)$ & $15(2-40)$ & 0.90 & $9(2-34)$ & $9(3-22)$ & 0.37 \\
Child-Pugh score, $\mathrm{n}$ & 23 & 24 & $>0.99$ & 36 & 36 & $>0.99$ \\
A & 3 & 3 & 0 & 0 & \\
B & 3 & & & 0 & \\
\hline
\end{tabular}

organic anion-transporting polypeptide 8 (OATP8) expression varied according to tumor differentiation (5). Conversely, CRLM displayed only a rim pattern, since normal cells surrounding the tumor were compressed by the tumor, causing cholestasis. In our cohort, the total fluorescent type was more common in well-differentiated hepatocellular carcinomas than in other types (Table III). In addition to the three fluorescent types, we identified combined types, having both cancerous fluorescent and rim patterns, which include the total or partial fluorescence and rim fluorescence types (Table II).

Several previous studies have confirmed the surgical margin to be free of cancer cells in rim-positive HCC and CRLM cases $(6,8,12)$. The results of our study provide the fluorescence microscopical support to this finding. Thus, the fluorescent area in the rim fluorescent pattern suggests a negative surgical margin, which may be secured if this rim fluorescence area is not exposed during liver resection. We classified surgical specimens into rim-positive and rim-negative fluorescence patterns. Cases with the rim-positive fluorescent pattern had significantly less advanced fibrosis than those with the rimnegative fluorescent pattern (Table IV). Similar results were shown by a previous report (21). However, it is unclear whether there is any relation between ICG fluorescence and fibrosis in non-cancerous liver parenchyma.

Additionally, the width of fluorescence is important for the surgeon while securing the surgical margin. In CRLM, $\mathrm{R} 0$ resections are commonly further subdivided according to whether the cancer cell-free surgical margin is $1 \mathrm{~mm}$ or less 
A

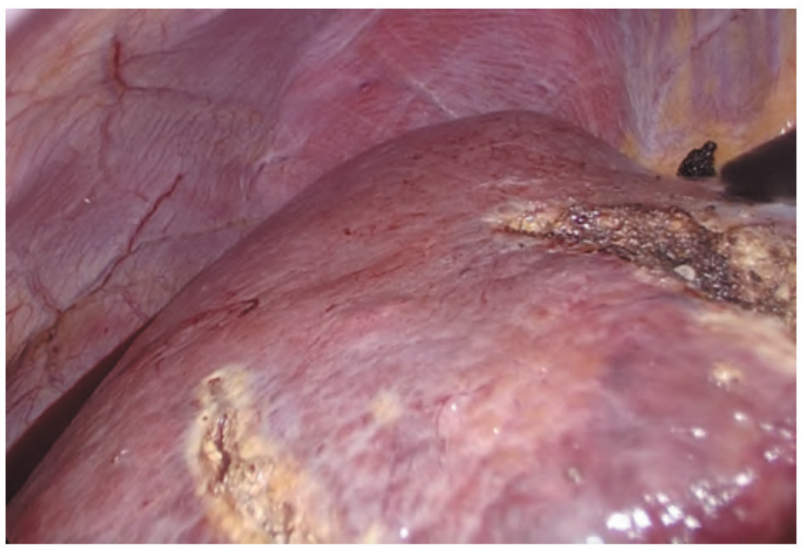

C

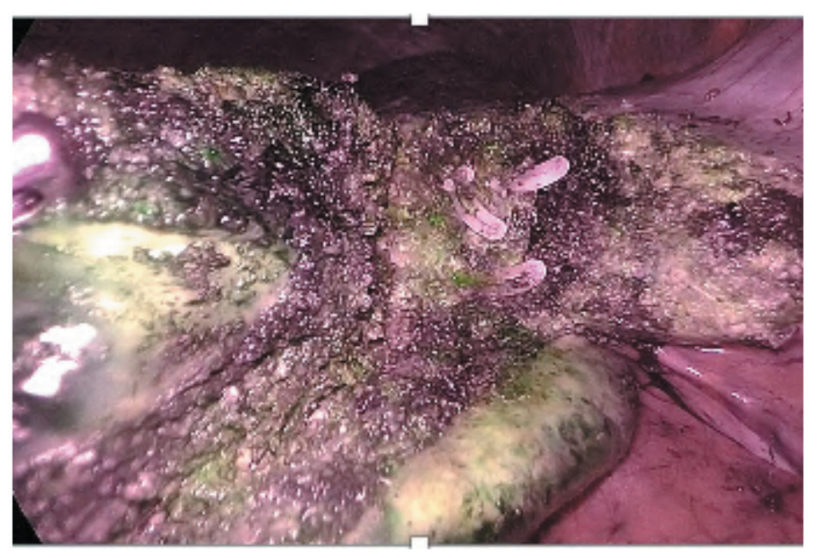

D

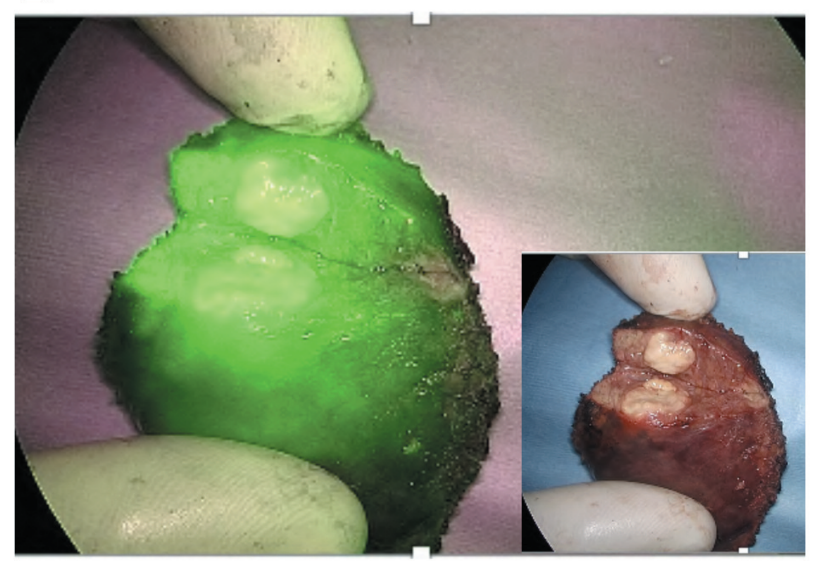

$\mathbf{F}$

E
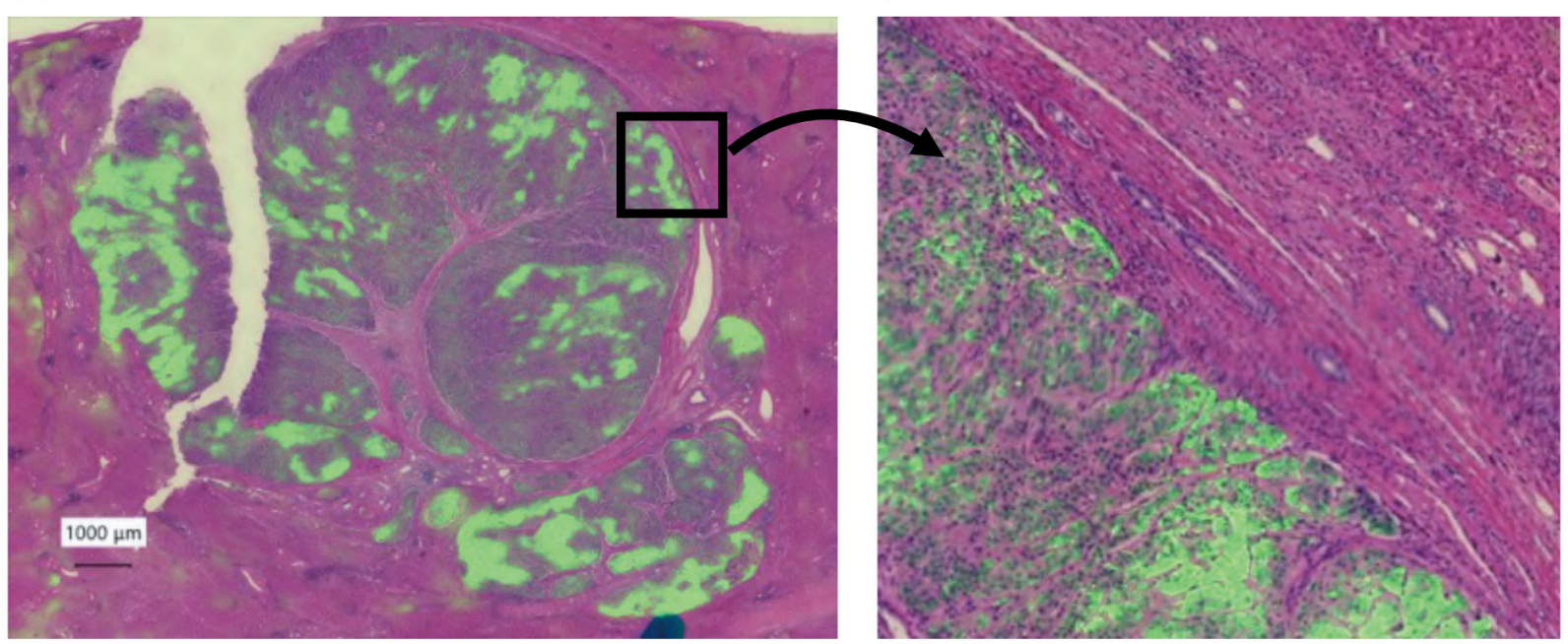

Figure 2. Intraoperative and microscopic fluorescence findings in hepatocellular carcinoma: Partial fluorescent type; HCC in segment 4 of a 64 year-old male. A: Normal laparoscopic color image. B: Near-infrared fluorescence image; fluorescence detected on the liver surface (white arrow). $C$ : Liver parenchyma during liver resection; no NIR fluorescence on the transected parenchymal surface. D: Cut surface showing fluorescence on the surgical specimen. E: Fluorescence microscopy image (originally $\times 1$ ); partial fluorescent type. F: Magnified image; securing the surgical margin with no fluorescence in the noncancerous liver tissue. 
A

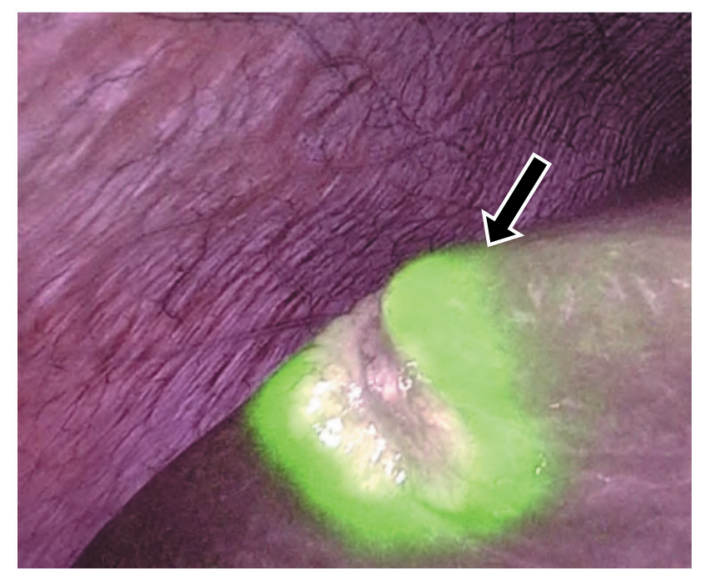

C

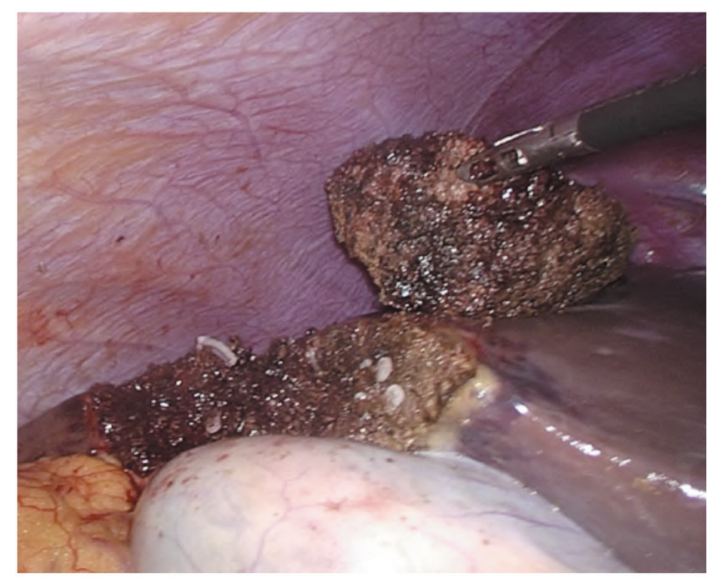

\section{B}

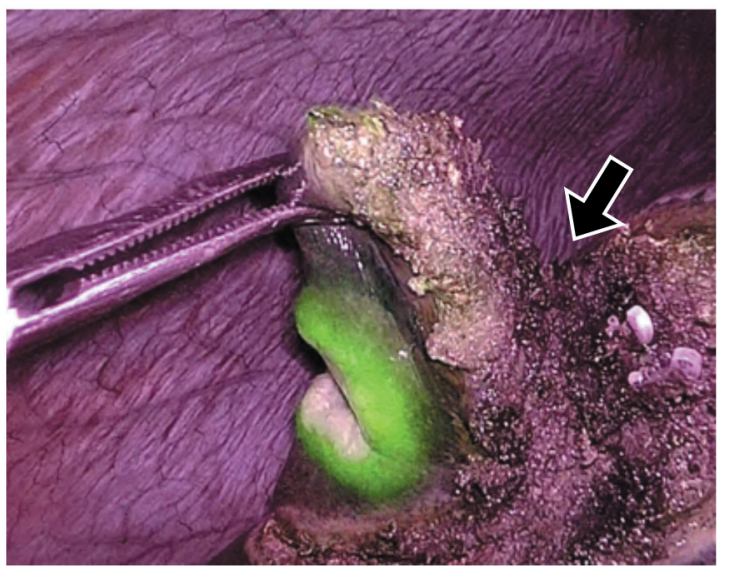

D

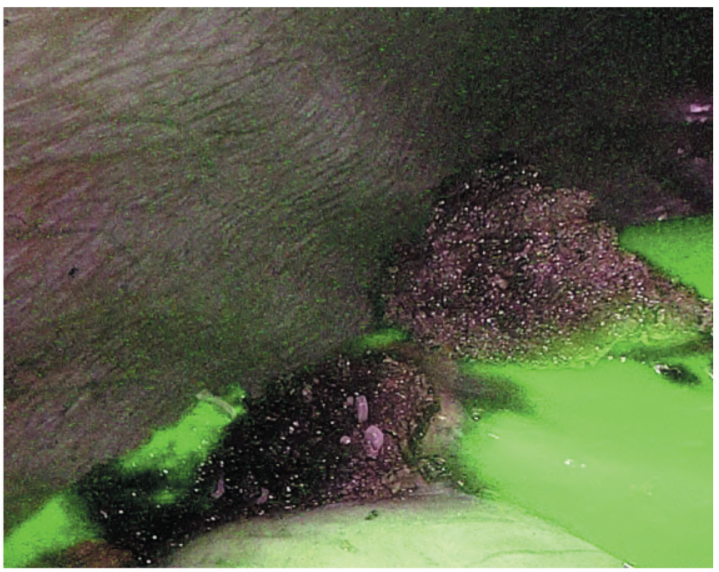

E $\mathbf{F}$

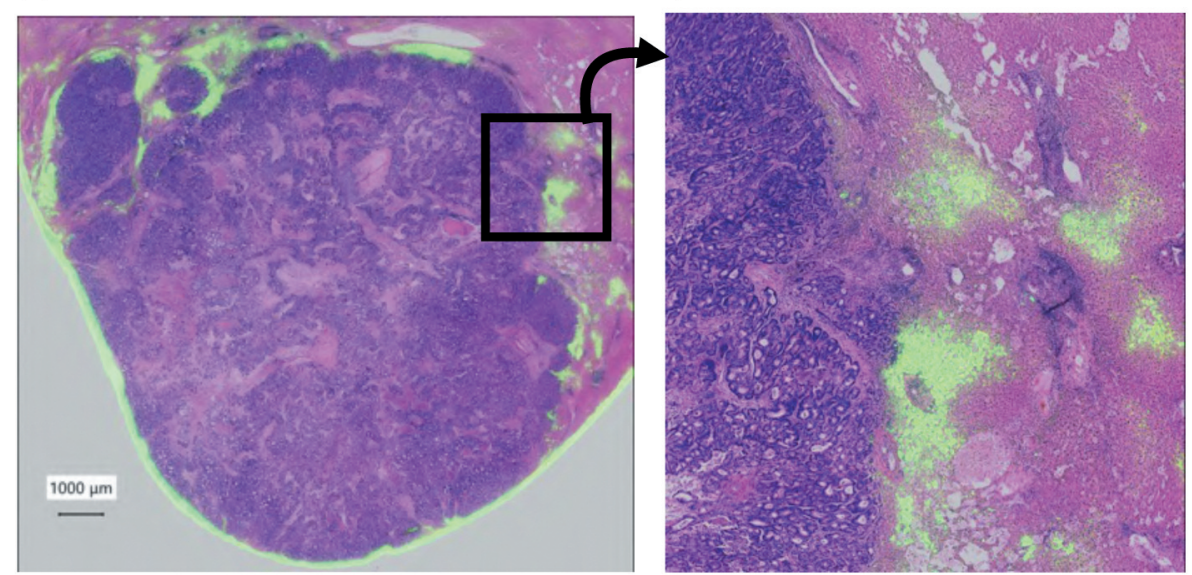

Figure 3. Intraoperative and microscopic fluorescence findings in colorectal liver metastasis (CRLM): Rim fluorescent type; CRLM in segment 4 of a 64-year-old male. A: NIR fluorescence image; determination of tumor demarcation (black arrow). B: Liver parenchyma during liver resection; no near-infrared fluorescence on the transected parenchymal surface. C: Normal laparoscopic color image after resection. D: No near-infrared fluorescence on the transected parenchymal surface. E: Fluorescent microscopy image (originally x1), rim fluorescent type. F: Magnified image; securing the surgical margin with fluorescence in the noncancerous liver tissue. 
Table VIII. Exhibition of fluorescence signal in colorectal liver metastasis as detected by fluorescence microscopy.

\begin{tabular}{lccc}
\hline & $\begin{array}{c}\text { Detection } \\
\mathrm{n}=36\end{array}$ & $\begin{array}{c}\text { Non-detection } \\
\mathrm{n}=36\end{array}$ & $\begin{array}{c}p \text {-Value } \\
-\end{array}$ \\
\hline $\begin{array}{l}\text { ICG dosing } \\
\text { ICG R15 } \\
\quad \text { Median (range) }\end{array}$ & $0.5 \mathrm{mg} / \mathrm{kg}$ i.v. & $0.5 \mathrm{mg} / \mathrm{kg}$ i.v. & - \\
$\begin{array}{l}\text { Child-Pugh score, } \mathrm{n} \\
\text { A }\end{array}$ & $9(2-34)$ & $9(3-22)$ & 0.37 \\
$\mathrm{~B}$ & 36 & 36 & $>0.99$ \\
\hline
\end{tabular}

ICG R15: Indocyanine green retention rate at $15 \mathrm{~min}$.

(22-24). The width of fluorescence was $\geq 1 \mathrm{~mm}$ and $<1 \mathrm{~mm}$ from the tumor margin in $28(77.8 \%)$ and eight $(22.2 \%)$ cases, respectively. As mentioned previously, all cases were pathologically free of malignant cells.

Overall in our study, the median width of fluorescence from the edge in CRLM was 1,608 $\mu \mathrm{m}$ (range=304-7467 $\mu \mathrm{m})$. Usually, the surgical margin is considered to be pathologically secure if the fluorescence signal is not exposed. The fluorescence width did not differ significantly between HCC and CRLM. The median fluorescence width from the edge in $\mathrm{HCC}$ cases with a rim fluorescence pattern was $2,159 \mu \mathrm{m} \quad$ (range $=378-110,100 \mu \mathrm{m})$, and the fluorescence width was $0 \mathrm{~mm}$ in $11(42.3 \%)$ cases with a rim-negative fluorescence pattern (Table VI). Therefore, in rim-negative cases, the ultimate care should be exercised not to breach the HCC capsule and the absent of rim fluorescence should be kept in mind during fluorescenceguided liver resection.

In this study, we successfully evaluated the fluorescence in liver specimens and the surrounding tissue using a fluorescence microscope. These results form the basis for ICG fluorescence research and fluorescence-guided surgery in various organs. However, this study has some limitations. Fluorescent signals by fluorescence microscopy were not identified in half of the samples ( 27 out of 53 cases of HCC and 36 out of 72 cases of CRLM). The period from surgery to observation differed among the cases, as these samples were reviewed retrospectively. We were able to observe fluorescence in a paraffin-embedded tumor tissue sample that was obtained more than 4 years earlier. In contrast, we did not observe fluorescence in some samples that were obtained 1 year earlier. However, the optimal conditions necessary to preserve the fluorescence intensity in paraffin-embedded tissues and specimens were not investigated. Further studies are necessary to determine the optimal conditions for preserving the fluorescence signal, including the concentration of ICG and the interval between ICG injection and the operation. However, we demonstrated that ICG fluorescence in paraffin-embedded tissue samples may be retrospectively observed; this is essential for further research and development in this field.

In conclusion, our data show that NIR imaging is a reliable navigation tool for identifying surgical margins in liver surgery. Pathologically, the surgical margin is secured if fluorescence is not exposed. In HCC, when the liver is in an advanced stage of fibrosis, a rim-positive pattern may not be evident. Surgeons should be careful as certain HCC cases do not demonstrate capsule formation or invasion. In this study, the observation of ICG fluorescence in the tissue sections was more apparent and broader than in previous pathological reports. This may potentially contribute to the development of a new approach for ICG uptake and excretion mechanisms.

\section{Conflicts of Interest}

All Authors declare that they have no conflicts of interest.

\section{Authors' Contributions}

Y.T., T.A and H.T designed and performed experiments, analyzed data and wrote the article; T.K., D.A.M., T.K., K.M., K.Y., K.N., T.H., Y.W., H.S., K. T., T.Y., K.S., A.F., Y.E., R.M.H., and M.M. gave technical support and conceptual advice.

\section{Acknowledgements}

The Authors would like to thank Keyence (Osaka, Japan) for their help. This study was supported by the Showa University Research Grant for Young Researchers.

\section{References}

1 Tanaka E, Choi HS, Fujii H, Bawendi MG and Frangioni JV: Image-guided oncologic surgery using invisible light: completed pre-clinical development for sentinel lymph node mapping. Ann Surg Oncol 13: 1671-1681, 2006. PMID: 17009138. DOI: 10.1245/s10434-006-9194-6

2 Aoki T, Yasuda D, Shimizu Y, Odaira M, Niiya T, Kusano T, Mitamura K, Hayashi K, Murai N, Koizumi T, Kato H, Enami Y, Miwa M and Kusano M: Image-guided liver mapping using fluorescence navigation system with indocyanine green for anatomical hepatic resection. World J Surg 32: 1763-1767, 2008. PMID: 18543027. DOI: 10.1007/s00268-008-9620-y

3 Uchiyama K, Ueno M, Ozawa S, Kiriyama S, Shigekawa Y, Hirono S, Kawai M, Tani $M$ and Yamaue $H$ : Combined intraoperative use of contrast-enhanced ultrasonography imaging using a sonazoid and fluorescence navigation system with indocyanine green during anatomical hepatectomy. Langenbecks Arch Surg 396: 1101-1107, 2011. PMID: 21918930. DOI: 10.1007/s00423-011-0778-7

4 Ishizawa T, Tamura S, Masuda K, Aoki T, Hasegawa K, Imamura H, Beck Y and Kokudo N: Intraoperative fluorescent cholangiography using indocyanine green: A biliary road map for safe surgery. J Am Coll Surg 208: e1-4, 2009. PMID: 19228492. DOI: 10.1016/j.jamcollsurg.2008.09.024 
5 Ishizawa T, Masuda K, Urano Y, Kawaguchi Y, Satou S, Kaneko J, Hasegawa K, Shibahara J, Fukayama M, Tsuji S, Midorikawa Y, Aburatani $\mathrm{H}$ and Kokudo N: Mechanistic background and clinical applications of indocyanine green fluorescence imaging of hepatocellular carcinoma. Ann Surg Oncol 21: 440-448, 2014. PMID: 24254203. DOI: 10.1245/s10434-013-3360-4

6 Ishizawa T, Fukushima N, Shibahara J, Masuda K, Tamura S, Aoki T, Hasegawa K, Beck Y, Fukayama M and Kokudo N: Real-time identification of liver cancers by using indocyanine green fluorescent imaging. Cancer 115: 2491-2504, 2009. PMID: 19326450. DOI: $10.1002 /$ cncr.24291

7 Gotoh K, Yamada T, Ishikawa O, Takahashi H, Eguchi H, Yano M, Ohigashi H, Tomita Y, Miyamoto Y and Imaoka S: A novel image-guided surgery of hepatocellular carcinoma by indocyanine green fluorescence imaging navigation. J Surg Oncol 100: 75-79, 2009. PMID: 19301311. DOI: $10.1002 /$ jso. 21272

8 Aoki T, Murakami M, Koizumi T, Matsuda K, Fujimori A, Kusano T, Enami Y, Goto S, Watanabe M and Otsuka K: Determination of the surgical margin in laparoscopic liver resections using infrared indocyanine green fluorescence. Langenbecks Arch Surg 403: 671-680, 2018. PMID: 29915961. DOI: $10.1007 / \mathrm{s} 00423-018-1685-\mathrm{y}$

9 Morita Y, Sakaguchi T, Unno N, Shibasaki Y, Suzuki A, Fukumoto K, Inaba K, Baba S, Takehara Y, Suzuki S and Konno $\mathrm{H}$ : Detection of hepatocellular carcinomas with near-infrared fluorescence imaging using indocyanine green: its usefulness and limitation. Int J Clin Oncol 18: 232-241, 2013. PMID: 22200990. DOI: 10.1007/s10147-011-0367-3

10 Yokoyama N, Otani T, Hashidate H, Maeda C, Katada T, Sudo $\mathrm{N}$, Manabe S, Ikeno Y, Toyoda A and Katayanagi N: Real-time detection of hepatic micrometastases from pancreatic cancer by intraoperative fluorescence imaging: preliminary results of a prospective study. Cancer 118: 2813-2819, 2012. PMID: 21990070. DOI: $10.1002 /$ cncr.26594

11 van der Vorst JR, Schaafsma BE, Hutteman M, Verbeek FP, Liefers GJ, Hartgrink HH, Smit VT, Lowik CW, van de Velde CJ, Frangioni JV and Vahrmeijer AL: Near-infrared fluorescenceguided resection of colorectal liver metastases. Cancer 119: 34113418, 2013. PMID: 23794086. DOI: 10.1002/cncr.28203

12 Shimada S, Ohtsubo S, Ogasawara K and Kusano M: Macroand microscopic findings of ICG fluorescence in liver tumors. World J Surg Oncol 13: 198, 2015. PMID: 26055754. DOI: 10.1186/s12957-015-0615-5

13 Reich H, McGlynn F, DeCaprio J and Budin R: Laparoscopic excision of benign liver lesions. Obstet Gynecol 78: 956-958, 1991. PMID: 1833688.

14 Beppu T, Wakabayashi G, Hasegawa K, Gotohda N, Mizuguchi T, Takahashi Y, Hirokawa F, Taniai N, Watanabe M, Katou M, Nagano H, Honda G, Baba H, Kokudo N, Konishi M, Hirata K, Yamamoto M, Uchiyama K, Uchida E, Kusachi S, Kubota K, Mori M, Takahashi K, Kikuchi K, Miyata H, Takahara T, Nakamura M, Kaneko H, Yamaue H, Miyazaki M and Takada T: Long-term and perioperative outcomes of laparoscopic versus open liver resection for colorectal liver metastases with propensity score matching: a multi-institutional Japanese study. J Hepatobiliary Pancreat Sci 22: 711-720, 2015. PMID: 25902703. DOI: $10.1002 /$ jhbp.261

15 Takahara T, Wakabayashi G, Beppu T, Aihara A, Hasegawa K, Gotohda N, Hatano E, Tanahashi Y, Mizuguchi T, Kamiyama T, Ikeda T, Tanaka S, Taniai N, Baba H, Tanabe M, Kokudo N,
Konishi M, Uemoto S, Sugioka A, Hirata K, Taketomi A, Maehara Y, Kubo S, Uchida E, Miyata H, Nakamura M, Kaneko $\mathrm{H}$, Yamaue $\mathrm{H}$, Miyazaki $\mathrm{M}$ and Takada T: Long-term and perioperative outcomes of laparoscopic versus open liver resection for hepatocellular carcinoma with propensity score matching: a multi-institutional Japanese study. J Hepatobiliary Pancreat Sci 22: 721-727, 2015. PMID: 26096910. DOI: $10.1002 /$ jhbp. 276

16 Yoon YI, Kim KH, Cho HD, Kwon JH, Jung DH, Park GC, Song GW, Ha TY and Lee SG: Long-term perioperative outcomes of pure laparoscopic liver resection versus open liver resection for hepatocellular carcinoma: a retrospective study. Surg Endosc, 2019. PMID: 31161292. DOI: 10.1007/s00464-019-06831-w

17 Kitai T, Inomoto T, Miwa M and Shikayama T: Fluorescence navigation with indocyanine green for detecting sentinel lymph nodes in breast cancer. Breast Cancer 12: 211-215, 2005. PMID: 16110291. DOI: $10.2325 /$ jbcs.12.211

18 Kusano M, Tajima Y, Yamazaki K, Kato M, Watanabe M and Miwa M: Sentinel node mapping guided by indocyanine green fluorescence imaging: a new method for sentinel node navigation surgery in gastrointestinal cancer. Dig Surg 25: 103108, 2008. PMID: 18379188. DOI: 10.1159/000121905

19 Parungo CP, Ohnishi S, Kim SW, Kim S, Laurence RG, Soltesz EG, Chen FY, Colson YL, Cohn LH, Bawendi MG and Frangioni JV: Intraoperative identification of esophageal sentinel lymph nodes with near-infrared fluorescence imaging. J Thorac Cardiovasc Surg 129: 844-850, 2005. PMID: 15821653. DOI: 10.1016/j.jtcvs.2004.08.001

20 Rubens FD, Ruel M and Fremes SE: A new and simplified method for coronary and graft imaging during CABG. Heart Surg Forum 5: 141-144, 2002. PMID: 12114127.

21 Kaibori M, Ishizaki M, Matsui K and Kwon AH: Intraoperative indocyanine green fluorescent imaging for prevention of bile leakage after hepatic resection. Surgery 150: 91-98, 2011. PMID: 21514613. DOI: 10.1016/j.surg.2011.02.011

22 Pawlik TM, Scoggins CR, Zorzi D, Abdalla EK, Andres A, Eng C, Curley SA, Loyer EM, Muratore A, Mentha G, Capussotti L and Vauthey JN: Effect of surgical margin status on survival and site of recurrence after hepatic resection for colorectal metastases. Ann Surg 241: 715-722, 2005. PMID: 15849507. DOI: 10.1097/01.sla.0000160703.75808.7d

23 Hamady ZZ, Lodge JP, Welsh FK, Toogood GJ, White A, John $\mathrm{T}$ and Rees M: One-millimeter cancer-free margin is curative for colorectal liver metastases: a propensity score case-match approach. Ann Surg 259: 543-548, 2014. PMID: 23732261. DOI: $10.1097 /$ SLA.0b013e3182902b6e

24 Qadan M and D'Angelica MI: Extending the limits of resection for colorectal liver metastases: positive resection margin and outcome after resection of colorectal cancer liver metastases. J Gastrointest Surg 21: 196-198, 2017. PMID: 27586189 DOI: 10.1007/s11605-016-3253-5 